\title{
HIV and decreased risk of multiple sclerosis: role of low CD4+ lymphocyte count and male prevalence
}

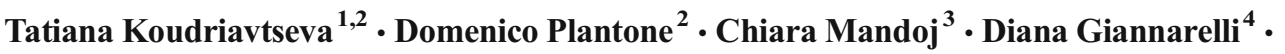 \\ Alessandra Latini ${ }^{5} \cdot$ Manuela Colafigli $^{5} \cdot$ Elisabetta Trento $^{6} \cdot$ Paola Cordiali-Fei $^{6}$. \\ Fulvia Pimpinelli ${ }^{6}$
}

Received: 26 April 2016/Revised: 6 June 2016 / Accepted: 1 July 2016

(C) Journal of NeuroVirology, Inc. 2016
Keywords Multiple Sclerosis $\cdot$ HIV positive dermatological patients $\cdot$ circulating lymphocytes $\cdot \mathrm{CD} 4+$ count $\cdot$ gender

\section{Introduction}

Human immunodeficiency virus (HIV) infection has been reported to decrease the risk of developing multiple sclerosis (MS) (Gold et al. 2015). HIV-related immunodepression and highly active antiretroviral treatment (HAART) have been advocated as possible determinants to explain this negative association. Furthermore, these diseases show opposite gender prevalence since HIV infection is more frequent in men while MS mainly affects women.

HIV infection is characterized by progressive CD4+ T lymphocyte loss leading to the development of opportunistic infections, cancers and death in untreated patients. CD8+ cells contribute to establishing viral control due to their remarkable survival and expansion capacity (Chakrabarti and Simon 2010; Poropatich and Sullivan 2011). MS is considered a CD4+ Th1/Th17-mediated inflammatory disease, but an important role of both CD8+ T (Frisullo et al. 2011) and CD19+ B cells (Cross and Waubant 2011) has been demonstrated. Finally, innate immunity and in particular natural killer (NK) cells are involved in the pathogenesis of both MS and HIV infection (Schleinitz et al. 2010; Altfeld et al. 2011).

This is a retrospective case-control study comparing the number of circulating CD4+, CD8+, CD19+ and NK lymphocytes among patient groups with a different immunocompetent status - naive HIV, treated HIV, treated MS and untreated MS - and healthy controls. We also compared lymphocyte subpopulations between males and females within every group and evaluated the correlations of each lymphocyte subset number with participant's demographic and clinical features. Since a decrease in CD4+ count is a main feature of untreated HIV, 
we hypothesized that a low CD4+ cell number may be determinant in the reported decreasing HIV effect on MS risk.

\section{Materials and methods}

\section{Participants}

We retrospectively included 58 consecutive HIV and 46 relapsing-remitting MS patients (Polman et al. 2011) that we followed at our clinic and 31 healthy controls (workers) with similar demographic features selected from our laboratory database. We excluded subjects affected by cancer, other infectious, inflammatory or immune system pathologies, and those treated with corticosteroids or immunosuppressive drugs during the prior 3 months. All patients and controls freely gave their informed consent. The study was approved by the IFO Ethics Committee.

\section{Analysis of peripheral blood mononuclear cells}

The analysis of immune cell subsets in peripheral blood was performed by flow cytometry using a six-colour (CD45/CD3/ CD4/CD8; CD45/CD3/CD19/CD16-56) single platform immune staining kit (TBNK reagent and Trucount tubes, FACSCalibur; BD Biosciences, San Jose, CA, USA).

\section{HIV viral load}

Viral load was estimated with real-time polymerase chain reaction (PCR) testing that uses the $\mathrm{COBAS}^{\circledR}$ AmpliPrep Instrument to automate sample processing and the COBAS $^{\circledR}{ }^{\circledR}$ TaqMan ${ }^{\circledR}$ Analyzer to automate amplification and detection (Roche Diagnostics GmbH, Manheim, Germany). The assay can quantitate HIV-1 RNA over a range of 20-10,000,000 copies/mL, and the result was described as the number of copies of HIV RNA per millilitre (ml). If the viral load was below the lower detectable limit of 20 copies/ml, the HIV patient was considered a "virologic responder"; if the viral load was over the 20 copies $/ \mathrm{ml}$, the patient was considered a "virologic non-responder".

\section{Statistical analysis}

Descriptive variables were defined as means \pm standard deviation (SD). Statistical analysis was performed by Student's $t$ test or one-way analysis of variance (ANOVA). If the ANOVA showed a statistical difference between subgroups, a post hoc analysis using Bonferroni correction for multiple comparisons was performed. Correlations were estimated by Pearson's coefficient $(p<0.05)$. Level of significance was set at $p \leq 0.05$ (SPSS version 20.0, SPSS Inc., Chicago, IL, USA).

\section{Results}

Demographic, clinical characteristics and immunological data of whole groups of healthy controls, MS and HIV patients are summarized in Table 1. Women were prevalent in MS group and men in HIV group according to a typical female/male ratio in these two diseases.

\section{Comparisons of circulating CD4+, CD8+, CD19+ and NK cells numbers among participant's groups}

As expected, both $\mathrm{CD} 4+$ cell count and $\mathrm{CD} 4 / \mathrm{CD} 8$ ratio were lower while $\mathrm{CD} 8+$ cell number was higher in HIV patients compared to MS patients and controls. NK cells were lower in MS patients compared to controls (Table 1).

Eighteen HIV patients were naïve-untreated, and 40 were HAART-treated including 24 virologic responders and 16 non-responders. Twenty-eight MS patients (15 remitting and 13 relapsing) were untreated, and 18 patients ( 8 remitting and 10 relapsing) were treated with immunomodulatory drugs such as interferon- $\beta$ and glatiramer acetate. The majority of remitting and relapsing MS patients were moderately disabled as measured by Expanded Disability Status Scale [median (range) $2.0(1.0-5.5)$ and 3.0 (1.5-6.5), respectively].

Untreated HIV patients had a higher CD8+ cell number and both a lower CD4+ cell number and CD4/CD8 ratio $(p<0.0001)$ compared to controls (Table 2 and Fig. 1). HAART-treated HIV patients had a higher CD8+ cell number and a lower $\mathrm{CD} 4 / \mathrm{CD} 8$ ratio $(p<0.0001)$ compared either to controls, treated and untreated MS groups and a higher $\mathrm{CD} 4+$ number with respect to untreated HIV patients and a higher NK cell number compared to treated MS patients.

Untreated MS patients had no significant difference in the number of all lymphocytes subsets compared to controls (Table 2 and Fig. 1). They had a higher number of CD4+ and $\mathrm{CD} 19+$ cells, a higher $\mathrm{CD} 4 / \mathrm{CD} 8$ ratio $(p<0.0001)$ and a lower number of CD8+ cells as compared to untreated HIV patients. Treated MS patients showed a lower number of $\mathrm{CD} 4+, \mathrm{CD} 8+$ and NK lymphocytes compared to those untreated as well as compared to controls.

There were no differences in the number of circulating lymphocytes or $\mathrm{CD} 4 / \mathrm{CD} 8$ ratio between remitting and relapsing MS patients as well as between HIV responders and nonresponders.

There was no significant difference for each lymphocyte subset between females and males within the groups of controls, treated and untreated HIV and treated and untreated MS patients. However, a CD4+ cell number was no significantly higher in women compared to men in every group except HIV non-responders, in which it was no significantly higher in men. 
Table 1 Demographic and clinical characteristics, circulating lymphocyte subset number of participant's groups

\begin{tabular}{|c|c|c|c|c|c|c|}
\hline Variable & Healthy controls $n=31$ & MS patients $n=46$ & HIV patients $n=58$ & $p$ value $^{\mathrm{a}}$ & $p$ value $^{\mathrm{b}}$ & $p$ value $^{\mathrm{c}}$ \\
\hline Females/males & $18 / 13$ & $36 / 10$ & $6 / 52$ & NS & $<0.0001$ & $<0.0001$ \\
\hline Age years $($ mean $\pm \mathrm{SD})$ & $45.9 \pm 9.8$ & $43.0 \pm 11.1$ & $43.6 \pm 11.8$ & NS & NS & NS \\
\hline Disease duration months (mean \pm SD) & NA & $126.1 \pm 81.5$ & $96.7 \pm 80.8$ & NA & NA & NS \\
\hline $\mathrm{CD} 4$ cells $/ \mathrm{ml}($ mean $\pm \mathrm{SD})$ & $870 \pm 242$ & $768 \pm 405$ & $619 \pm 269$ & NS & 0.002 & 0.05 \\
\hline $\mathrm{CD} 8$ cells $/ \mathrm{ml}($ mean $\pm \mathrm{SD})$ & $538 \pm 236$ & $392 \pm 199$ & $925 \pm 374$ & NS & $<0.0001$ & $<0.0001$ \\
\hline CD19 cells/ml (mean $\pm \mathrm{SD})$ & $206 \pm 88$ & $243 \pm 126$ & $212 \pm 117$ & NS & NS & NS \\
\hline $\mathrm{CD} 4 / \mathrm{CD} 8$ ratio $($ mean $\pm \mathrm{SD})$ & $1.8 \pm 0.6$ & $2.1 \pm 0.8$ & $0.8 \pm 0.4$ & NS & $<0.0001$ & $<0.0001$ \\
\hline $\mathrm{NK}$ cells $/ \mathrm{ml}($ mean $\pm \mathrm{SD})$ & $251 \pm 85$ & $185 \pm 102$ & $225 \pm 116$ & 0.01 & NS & NS \\
\hline
\end{tabular}

The differences between the groups were analyzed using chi-square test for categorical variables and Student's $t$ test for quantitative items $M S$ multiple sclerosis, $H I V$ human immunodeficiency virus, $S D$ standard deviation, $N A$ not applicable, $N S$ not significant, $N K$ natural killer ${ }^{a} p$ value represents differences between MS patients and healthy controls ${ }^{\mathrm{b}} p$ value represents differences between HIV patients and healthy controls ${ }^{\mathrm{c}} p$ value represents differences between the MS and HIV patients

Female HIV responders compared to non-responders had a lower number of circulating CD8+ cells (number \pm SD 668 \pm 94 vs. $1166 \pm 93$ cells $/ \mathrm{ml}, p=0.004)$ and a higher $\mathrm{CD} 4 / \mathrm{CD} 8$ ratio ( $1.3 \pm 0.2$ vs. $0.4 \pm 0.1, p=0.002)$. No significant difference in lymphocyte subset or CD4/CD8 ratio was found between responders and non-responders men.

There was a lower $\mathrm{CD} 4 / \mathrm{CD} 8$ ratio in relapsing compared to remitting women $(1.8 \pm 0.6$ vs. $2.3 \pm 0.6, p=0.02)$ and no significant differences between relapsing and remitting men.

\section{Correlations between CD4+, CD8+, CD19+, NK cell number and demographic and clinical characteristics of participants}

We found a positive correlation between NK cells number and age of treated HIV patients ( $p=0.007$ Rho 0.421 ). In treated MS patients, disease duration positively correlated with NK cells number ( $p=0.02$, Rho 0.551$)$. In remitting MS patients, disease duration negatively correlated with $\mathrm{CD} 4+$ and CD19+ cell number $(p=0.049$ Rho -0.415 and $p=0.03$ Rho -0.446 , respectively).

\section{Discussion}

We compared the number of circulating lymphocyte subsets among groups of HIV and MS patients with a different immune status - naive HIV, treated HIV, treated MS and untreated MS - and the healthy controls assuming that the partial immune recovery of treated HIV patients could be closer to relative immunosuppression of treated MS patients whereas the immunosuppressive condition of naive HIV patients may be more different from the immune status of untreated MS. Indeed, our treated MS patients showed a reduced number of $\mathrm{CD} 4+, \mathrm{CD} 8+$ and NK lymphocytes compared to those untreated.

As expected, the mean number of CD4+ lymphocytes was similar between treated MS and HIV patients but differed between untreated HIV and MS patients. The number of
Table 2 Circulating lymphocyte subsets number of MS treated and untreated patients, HIV treated and untreated patients and healthy controls

\begin{tabular}{|c|c|c|c|c|c|}
\hline \multirow[t]{2}{*}{ Variable } & \multirow{2}{*}{$\begin{array}{l}\text { Healthy controls } \\
n=31\end{array}$} & \multicolumn{2}{|c|}{ MS patients $n=46$} & \multicolumn{2}{|c|}{ HIV patients $n=58$} \\
\hline & & $\begin{array}{l}\text { Treated } \\
n=18\end{array}$ & $\begin{array}{l}\text { Untreated } \\
n=28\end{array}$ & $\begin{array}{l}\text { Treated } \\
n=40\end{array}$ & $\begin{array}{l}\text { Untreated } \\
n=18\end{array}$ \\
\hline $\mathrm{CD} 3$ cells $/ \mathrm{ml}($ mean $\pm \mathrm{SD})$ & $1464 \pm 382$ & $940 \pm 443$ & $1286 \pm 563$ & $1688 \pm 488$ & $1394 \pm 525$ \\
\hline $\mathrm{CD} 4$ cells/ml $($ mean $\pm \mathrm{SD})$ & $870 \pm 242$ & $612 \pm 298$ & $868 \pm 437$ & $699 \pm 259$ & $440 \pm 200$ \\
\hline $\mathrm{CD} 8$ cells/ml $($ mean $\pm \mathrm{SD})$ & $538 \pm 236$ & $310 \pm 165$ & $445 \pm 203$ & $940 \pm 356$ & $890 \pm 419$ \\
\hline $\mathrm{CD} 19$ cells $/ \mathrm{ml}($ mean $\pm \mathrm{SD})$ & $206 \pm 88$ & $226 \pm 108$ & $253 \pm 137$ & $236 \pm 122$ & $157 \pm 85$ \\
\hline $\mathrm{CD} 4 / \mathrm{CD} 8$ ratio $($ mean $\pm \mathrm{SD})$ & $1.8 \pm 0.6$ & $2.2 \pm 0.9$ & $2.0 \pm 0.7$ & $0.8 \pm 0.4$ & $0.6 \pm 0.4$ \\
\hline $\mathrm{NK}$ cells/ml (mean $\pm \mathrm{SD})$ & $251 \pm 85$ & $133 \pm 57$ & $218 \pm 111$ & $229 \pm 111$ & $215 \pm 130$ \\
\hline
\end{tabular}

$M S$ multiple sclerosis, $H I V$ human immunodeficiency virus, $S D$ standard deviation, $N K$ natural killer 
Fig. 1 Comparisons of lymphocyte subsets number (cells/mmc) between healthy controls, HIV-infected naive and treated patients, multiple sclerosis treated and untreated patients. $p$ value refers to Student's $t$ test. $M S$ multiple sclerosis, $H I V$ human immunodeficiency virus, CTRLs healthy controls, $N K$ natural killer
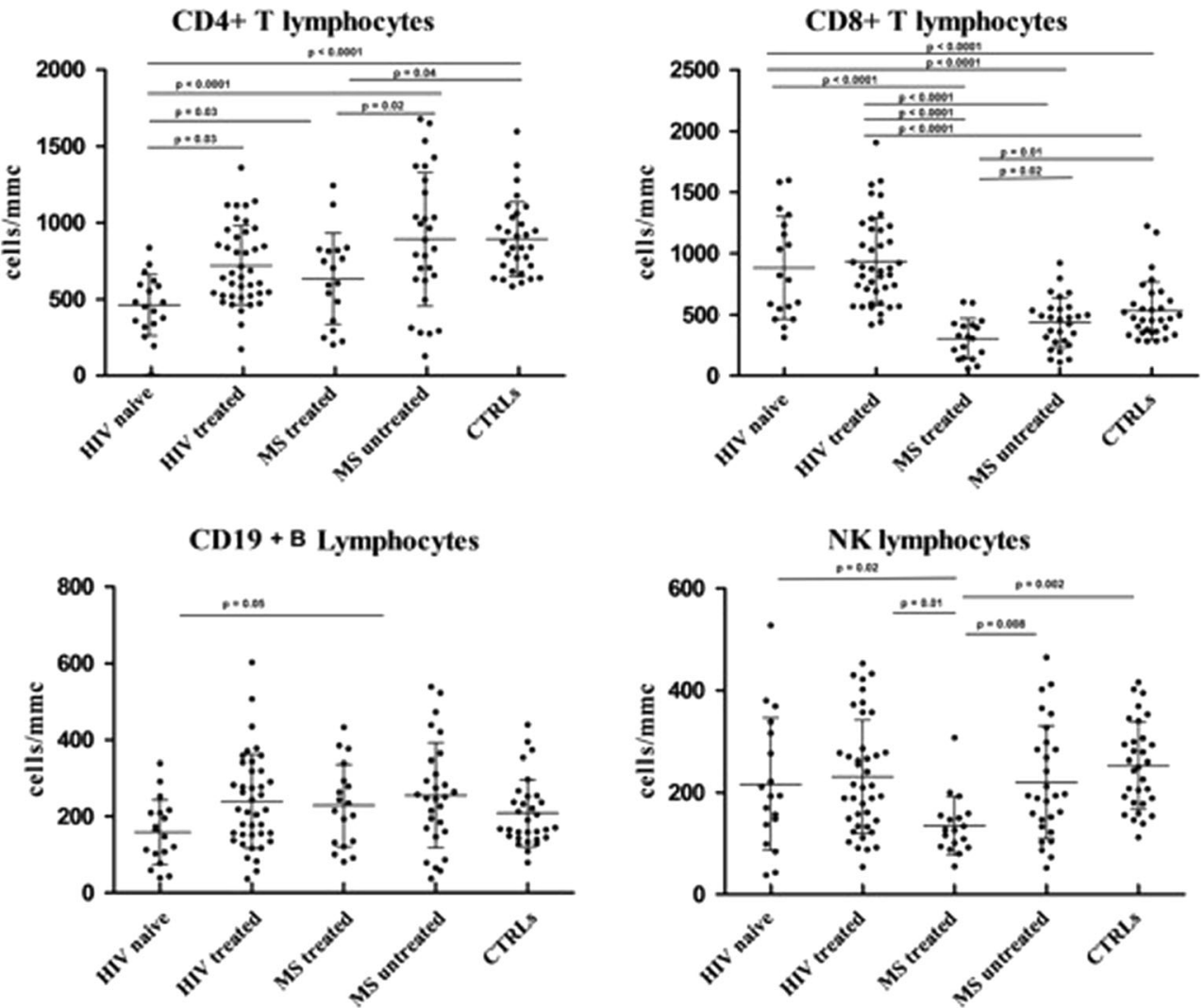

CD19+ lymphocytes had a similar trend of CD4+ lymphocytes. Conversely, a reduction of both CD8+ and NK cell number was found only in treated MS subgroup compared to all the others, likely reflecting the effect of the therapy.

From these data, we can hypothesize that CD4+ cells play a major role in decreasing the risk of MS in HIV patients. Previous papers have reported that the patients with a codiagnosis of HIV and MS have usually normal CD4+ cell count or at least not less than 500 cells/mm (GonzálezDuarte et al. 2011; Chin 2015), which usually occurs on HAART. Other works have described MS-like disorder started in the initial phase of HIV infection when the immune response is still preserved (Delgado et al. 2014).

The timing of HIV and MS co-diagnosis fully reflects a staging of association between HIV and autoimmune disorders related to the total CD4+ count as proposed by Zandman-Goddard and Shoenfeld (Zandman-Goddard and Shoenfeld 2002). During the initial acute HIV infection, autoimmune diseases may occur. This possibility is less frequent during the "quiescent period", characterized by a declining CD4+ count, and during the following stage, characterized by an immunosuppressive status with AIDS development, low CD4+ count and CD8+ cells predominance. During HAART, there is a restoration of immune competence and autoimmune diseases occur again.

It has been proposed that rapid immune reconstitution after the early phase of potent HAART regimens may be determinant in development of a substantial number of progressive multifocal leukoencephalopathy (PML) cases and associated with their poor outcome (Cinque et al. 2003). Likewise, occasional contrast-enhancing MRI lesions in asymptomatic patients diagnosed as PML-unrelated leukoencephalopathy have been also observed after a few weeks of HAART (Cinque et al. 2003). Two pathological reactions associated with the immune reconstitution in PML have been also reported in the same patient: active inflammatory lesions with abundant JC virus and acute perivenous leukoencephalitis devoid of JC virus (Vendrely et al. 2005).

Since there is opposite gender prevalence in MS and HIV, we compared the lymphocyte subsets between females and males in each group. In the healthy subjects, a higher CD4+ cell count and a lower NK cell count were previously showed in females compared to males under or equal to 50 years (Jentsch-Ullrich et al. 2005), and a significantly higher CD4/ CD8 ratio was found in adult females than males (Valiathan et al. 2014). In our study, CD4+ cell count was higher in women compared to men in all participant groups (except HIV non-responders); however, this difference did not reach the significance, probably due to the small sample size. Conversely, despite the scarce number of HIV female patients, there was a remarkable difference in the CD4/CD8 ratio between female responders and non-responders. Similarly, CD4/ CD8 ratio was higher in remitting compared to relapsing MS females. These results may reflect greater immune changes in 
females than in males, possibly due to their hormone fluctuations, which would predispose them during childbearing age to relapsing-remitting autoimmune diseases. Our data also suggest that women fail to control viral replication only during the severe stages of adaptive immunity depression, characterized by considerable decrease of both CD4+ cells and CD4/ CD8 ratio. The low female prevalence in HIV infection could not be due only to epidemiological reasons but also to their immune characteristics.

Finally, we found that NK cells correlate with either age in treated HIV patients and with disease duration in treated MS patients. The positive correlation between NK cells and age in our HIV patients confirms the previous data on expansion of functionally anergic NK cells described since the early phases of HIV infection (Alter et al. 2005; Mavilio et al. 2005). Similarly, the positive correlation between disease duration and NK cells in treated MS patients could be due to a progressive expansion of functionally impaired NK cells. A remarkable impairment of NK functional activity has been previously reported in MS (Morandi et al. 2008). Moreover, the negative correlation between disease duration and both $\mathrm{CD} 4+$ and CD19+ cell number in remitting patients possibly reflect a progressive adaptive immunity decline over disease course, which in part may be influenced by immunomodulatory therapy.

In conclusion, our study demonstrates that the reported decreasing effect of HIV infection on MS development is likely determined by the immunosuppressive status during HIV infection, characterized by a low CD4+ count and it is also influenced by the gender.

Acknowledgments TK, PC and FP conceived the study. CM, AL, MC and ET carried out the data collection. DG performed the statistical analysis. TK and DP wrote the manuscript. All authors commented on earlier versions of the manuscript and consented to the submission of the final draft.

\section{Compliance with ethical standards}

Conflict of interest The authors declare that they have no conflicts of interest. T. Koudriavtseva reports consulting fees from Bayer Schering, and Institutional grant from Merck Serono, Biogen Idec, Novartis, Bayer Schering outside the submitted work. Other authors have nothing to declare.

\section{References}

Alter G, Teigen N, Davis BT, Addo MM, Suscovich TJ, Waring MT, Streeck H, Johnston MN, Staller KD, Zaman MT, Yu XG, Lichterfeld M, Basgoz N, Rosenberg ES, Altfeld M (2005) Sequential deregulation of NK cell subset distribution and function starting in acute HIV-1 infection. Blood 106:3366-3369. doi:10.1182/blood-2005-03-1100

Altfeld M, Fadda L, Frleta D, Bhardwaj N (2011) DCs and NK cells: critical effectors in the immune response to HIV-1. Nat Rev Immunol 11:176-186. doi:10.1038/nri2935
Chakrabarti LA, Simon V (2010) Immune mechanism of HIV control. Curr Opin Immunol 22:488-496. doi:10.1016/j.coi.2010.06.006

Chin JH (2015) Multiple sclerosis and HIV-1 infection: case report of a HIV controller. J Neurovirol 21(4):464 467. doi:10.1007/s13365-015-0335-1

Cinque P, Bossolasco S, Brambilla AM, Boschini A, Mussini C, Pierotti C, Campi A, Casari S, Bertelli D, Mena M, Lazzarin A (2003) The effect of highly active antiretroviral therapy-induced immune reconstitution on development and outcome of progressive multifocal leukoencephalopathy: study of 43 cases with review of the literature. J Neurovirol 9(Suppl 1):73-80

Cross AH, Waubant E (2011) MS and the B cell controversy. Biochim Biophys Acta Mol basis Dis 1812:231-238. doi:10.1016/j. bbadis.2010.07.020

Delgado SR, Maldonado J, Rammohan KW (2014) CNS demyelinating disorder with mixed features of neuromyelitis optica and multiple sclerosis in HIV-1 infection. Case report and literature review. J Neurovirol 20:531-537. doi:10.1007/s13365-014-0260-8

Frisullo G, Plantone D, Marti A, Iorio R, Nociti V, Patanella AK, Batocchi AP (2011) Circulating CD8+CD56-perforin + T cells are increased in multiple sclerosis patients. J Neuroimmunol 240-241: 137-141. doi:10.1016/j.jneuroim.2011.09.002

Gold J, Goldacre R, Maruszak H, Giovannoni G, Yeates D, Goldacre M (2015) HIV and lower risk of multiple sclerosis: beginning to unravel a mystery using a record-linked database study. J Neurol Neurosurg Psychiatry 86:9-12. doi:10.1136/jnnp-2014-307932

González-Duarte A, Ramirez C, Pinales R, Sierra-Madero J (2011) Multiple sclerosis typical clinical and MRI findings in a patient with HIV infection. J Neurovirol 17:504-508. doi:10.1007/s13365-011-0054-1

Jentsch-Ullrich K, Koenigsmann M, Mohren M, Franke A (2005) Lymphocyte subsets' reference ranges in an age- and genderbalanced population of 100 healthy adults - a monocentric German study. Clin Immunol 116:192-197

Mavilio D, Lombardo G, Benjamin J, Kim D, Follman D, Marcenaro E, O'Shea MA, Kinter A, Kovacs C, Moretta A, Fauci AS (2005) Characterization of CD56-/CD16+ natural killer (NK) cells: a highly dysfunctional NK subset expanded in HIV-infected viremic individuals. Proc Natl Acad Sci U S A 102:2886-2891. doi:10.1073 /pnas.0409872102

Morandi B, Bramanti P, Bonaccorsi I, Montalto E, Oliveri D, Pezzino G, Navarra M, Ferlazzo G (2008) Role of natural killer cells in the pathogenesis and progression of multiple sclerosis. Pharmacol Res 57:1-5. doi:10.1016/j.phrs.2007.11.003

Polman CH, Reingold SC, Banwell B, Clanet M, Cohen JA, Filippi M, Fujihara K, Havrdova E, Hutchinson M, Kappos L, Lublin FD, Montalban X, O'Connor P, Sandberg-Wollheim M, Thompson AJ, Waubant E, Weinshenker B, Wolinsky JS (2011) Diagnostic criteria for multiple sclerosis: 2010 Revisions to the McDonald criteria. Ann Neurol 69:292-302. doi:10.1002/ana.22366

Poropatich K, Sullivan DJ (2011) Human immunodeficiency virus type 1 long-term non-progressors: the viral, genetic and immunological basis for disease non-progression. J Gen Virol 92:247-268. doi:10.1099/vir.0.027102-0

Schleinitz N, Vély F, Harlé JR, Vivier E (2010) Natural killer cells in human autoimmune diseases. Immunology 131:451-458. doi:10.1111/j.1365-2567.2010.03360.x

Valiathan R, Deeb K, Diamante M, Ashman M, Sachdeva N, Asthana D (2014) Reference ranges of lymphocyte subsets in healthy adults and adolescents with special mention of $\mathrm{T}$ cell maturation subsets in adults of South Florida. Immunobiology 219:487-496. doi:10.1016/j.imbio.2014.02.010

Vendrely A, Bienvenu B, Gasnault J, Thiebault JB, Salmon D, Gray F (2005) Fulminant inflammatory leukoencephalopathy associated with HAART-induced immune restoration in AIDS-related progressive multifocal leukoencephalopathy. Acta Neuropathol 109:449-455

Zandman-Goddard G, Shoenfeld Y (2002) HIV and autoimmunity. Autoimmun Rev 1:329-337. doi:10.1016/S1568-9972(02)00086-1 